\title{
Histopathological Changes in the Chorionic Villi and Endometrial Decidual Tissues in the Product of Conception of Spontaneous Abortion Cases. Makaju R, ${ }^{1}$ Shrestha $S,{ }^{1}$ Sharma $S,{ }^{1}$ Dhakal R, ${ }^{1}$ Bhandari $S,{ }^{1}$ Shrestha A, ${ }^{2}$ Tamrakar $S^{2}$
}

\author{
Corresponding Author \\ Ramesh Makaju \\ Department of Pathology \\ Dhulikhel Hospital, Kathmandu University Hospital \\ Dhulikhel, Kavre, Nepal. \\ E-mail: makajuram@gmail.com
}

Citation

Makaju R, Shrestha S, Sharma S, Dhakal R, Bhandari $\mathrm{S}$, Shrestha A et al. Histopathological Changes in the Chorionic Villi and Endometrial Decidual Tissues in the Product of Conception of Spontaneous Abortion Cases. Kathmandu Univ Med J 2015;52(4):357-60.

\begin{abstract}
\section{Background}

Spontaneous abortion refers to a pregnancy that ends spontaneously before the fetus has reached a viable gestational age or expulsion or extraction of an embryo or fetus weighing $500 \mathrm{~g}$ or less from its mother. The Maternal Mortality Morbidity Survey of Nepal 2008/09 reported that $7 \%$ of maternal deaths in Nepal were due to complications related to abortion.
\end{abstract}

\section{Objective}

The main objective of this study was to examine the histopathological changes in the chorionic villi and endometrial decidual tissue in products of conception obtained from women with spontaneous abortion.

\section{Method}

This is a retrospective study of 111 patients admitted in the Department of Obstetrics and Gynecology at Dhulikhel Hospital, Kathmandu University Hospital (DH-KUH) with the diagnosis of spontaneous abortion during the period of January 2013 to January 2014.

\section{Result}

Among 111 cases of spontaneous abortions, products of conception was seen in $73(65.77 \%)$ and with only one cases of choriocarcinoma. Majority of cases belongs to age group 21-30 years. The most common decidual changes were inflammation (41.4\%) followed by fibrin deposition $29.7 \%$. Majority of the cases shows hydropic changes as histopathological changes in chorionic villi. In the present study, minimum age of lady was 15 years and the maximum age was 45 years and the mean age was $25.09 \pm 5.58$ years at the time of abortion. Among the cases, maximum $69(62.2 \%)$ of them belonged to age group 21-30 years. Correlating the age group with number of abortions was found to be significantly different (Chi-square= 92.35, $d f=3, p<0.001$ ) among four different age groups.

\section{Conclusion}

The histopathological diagnosis of spontaneous abortion will help in further management of the patient. Further study is required to know the cause of different histopathlogical changes in villi as well as in the decidua.

\section{KEY WORDS}

Chorionic villi, endometrial decidual tissue, maternal mortality, product of conception, spontaneous abortion 


\section{INTRODUCTION}

The World Health Organization (WHO) defines spontaneous abortion as expulsion or extraction of an embryo or fetus weighing $500 \mathrm{~g}$ or less from its mother which occurs before the fetus has reached a viable gestational age. ${ }^{1-2}$

It is the most common complication of pregnancy and more than $80 \%$ of spontaneous abortion occurs in the first 12 weeks. ${ }^{3-6}$ According to Nepal Demographic Health Survey (NDHS) 2011, the majority of pregnancies (85\%) in Nepal end up in a live birth, while $8 \%$ of pregnancies aborted, $7 \%$ result in a spontaneous abortion and $1 \%$ end up in stillbirths. ${ }^{7}$ The Maternal Mortality Morbidity Survey of Nepal 2008/09 reported that $7 \%$ of maternal deaths in Nepal were due to complications related to abortion. ${ }^{7}$ Previous study has suggested different histopathological changes in the product of conception in the first trimester of pregnancy..$^{8-9}$ In addition, findings of histopathological examination could be helpful in the further management of those cases with the history of spontaneous abortion. ${ }^{10}$

Therefore, this study was conducted to examine the histopathological changes in the chorionic villi and endometrial decidual tissue in products of conception obtained from women with spontaneous abortion.

\section{METHODS}

This is a cross sectional study done in Dhulikhel Hospital, Kathmandu University Hospital (DH-KUH). All cases with the diagnosis of spontaneous abortion during the period of January 2013 to January 2014 were included in this study. Those cases with medical termination of pregnancy and ectopic pregnancy including those who failed to provided consent were excluded from this study.

The products of conception were received in $10 \%$ formalin at the department of pathology, Dhulikhel hospital. After gross examination of the specimen, tissue processing was done using automatic tissue processor. Specimens were processed and embedded in paraffin wax. The sections of 3-5 micrometer thickness were obtained and stained with Haematoxylin \& Eosin. All slides were examined by two pathologists separately and reported accordingly. Data was collected and presented as frequency and percentages tables. Data presented as mean \pm SD (standard deviation) and statistical analysis was performed using SPSS (Ver. 16.00) software wherever required. Data considered significant if $p<0.05$.

\section{RESULTS}

Total 111 cases of spontaneous abortions were included in the study among which most cases were found to be products of conception $73(65.8 \%)$ followed by decidua without chorionic villi $33(29.7 \%)$ and with only one cases of choriocarcinoma (Table 1).
Table 1. Frequency and percentage distribution by histopathological diagnosis

\begin{tabular}{|lc|}
\hline Histopathological diagnosis $(\mathbf{n = 1 1 1 )}$ & $\mathbf{N}(\%)$ \\
\hline Products of conception & $73(65.8)$ \\
\hline Decidua without chorionic villi & $33(29.7)$ \\
\hline Partial Hydatidiform mole & $2(1.8)$ \\
\hline Complete Hydatidiform mole & $2(1.8)$ \\
\hline Choriocarcinoma & $1(0.9)$
\end{tabular}

While analysing the histopathological changes in decidua, inflammation 46 (41.1\%) was found to be the most common cause and fibrin deposition was found in more than onethird of cases 33 (29.7\%; Table 2). The number of necrosis case was the least in our study.

Table 2. Frequency and percentage distribution by histopathological changes in decidua.

\begin{tabular}{|ll|}
\hline Histopathological changes in decidua $(\mathbf{n = 1 1 1 )}$ & $\mathbf{N}(\%)$ \\
\hline Inflammation & $46(41.4)$ \\
\hline Fibrin deposition & $33(29.7)$ \\
\hline Edema & $24(21.6)$ \\
\hline Hemorrhage & $24(21.6)$ \\
\hline Blood vessels thrombi & $6(5.4)$ \\
\hline Necrosis & $1(0.9)$ \\
\hline
\end{tabular}

Moreover, among 78 cases of decidua with chorionic villi (Table 3), hydrophic changes was the most common histopathological changes in chorionic villi (10\%) followed by fibrinoid degeneration (4.5\%). Molar changes (3.6\%) and polarized villi (3.6\%) are other histopathological changes found in chorionic villi (Table 3).

Table 3. Frequency and percentage distribution by histopathological changes in chorionic villi.

\begin{tabular}{|ll|}
\hline Histopathological changes in chorionic villi $(\mathbf{n}=\mathbf{7 8 )}$ & $\mathbf{N}(\%)$ \\
\hline Hydrophic changes & $11(9.9 \%)$ \\
\hline Fibrinoid degeneration & $5(4.5 \%)$ \\
\hline Molar changes & $4(3.6 \%)$ \\
\hline Polarized villi & $4(3.6 \%)$ \\
\hline Inflammation & $2(1.8 \%)$ \\
\hline Intervillous fibrosis & $1(0.9 \%)$ \\
\hline
\end{tabular}

The present study has shown that most cases were belonged to the age group 21-30 (62.2\%) whereas the least $(2.7 \%)$ was seen in age group $>40$ (Table 4$)$. To investigate the relation of number of abortions with age group, Chisquare test was performed which showed a significant value (Chi-square $=92.35, \mathrm{df}=3, \mathrm{p}<0.001$ ). The age group 21-30 has shown the significant relation with the number of abortions. 
Table 4. Case distribution by age group.

\begin{tabular}{|lll|}
\hline Age group in years $(\mathbf{n = 1 1 1})$ & $\mathbf{N}(\%)$ & $\begin{array}{l}\mathbf{p} \text {-value } \\
\text { (Chi- square test) }\end{array}$ \\
\hline$\leq 20$ & $27(24.3)$ & \\
\hline $21-30$ & $69(62.2)$ & $<0.001$ \\
\hline $31-40$ & $12(10.8)$ & \\
\hline$>40$ & $3(2.7)$ & \\
\hline
\end{tabular}

\section{DISCUSSION}

This study aims to investigate the histopathological changes in the product of conception from cases of spontaneous abortion. In agreement with previous studies the present study also has product of conception as the majority cases from those samples of spontaneous abortion. ${ }^{10,11}$ Those studies were investigating the relation of histopathological findings with tissue samples obtained from first-trimester miscarriage, ${ }^{11}$ and also exploring whether the routine histopathological examination is required to detect either an ectopic or molar pregnancy. ${ }^{10,12}$ Moreover, the histopathological assessment has great value in the identification of different diseases compared to clinical and laboratory findings. ${ }^{12}$

The present study has revealed that inflammation and fibrin deposition are the major findings in the histopathological examination of decidua. In agreement with our findings, previous study has suggested that frequent maternal immunological effect towards placental tissue can be the major cause of miscarriage during first-trimester. ${ }^{13}$ This study has demonstrated the lesions of chronic inflammation and uteroplacental vasculopathy in miscarriage cases with a first trimester loss. ${ }^{13}$ In addition, it has been suggested that systemic immune mediators can cause pregnancy failure by inhibiting ovarian hormone production. ${ }^{14}$ Therefore, our study suggests in controlling inflammatory response in those individual having recurrent spontaneous abortion as inflammation can be the key player in resulting miscarriage during first trimester and also has a link with reproductive endocrine systems. ${ }^{14}$

Moreover, further microscopic analysis of deciduas and chorionic villi revealed more cases of decidual inflammatory infiltrate followed by fibrin deposition. A previous study showed majority of cases as stromal fibrosis $83 \%$ followed by hydrophic changes in 52\% cases and reported $75 \%$ of cases as fibrinoid degeneration in chorionic villi. ${ }^{15} \mathrm{~A}$

\section{REFERENCES}

1. Regan L, Rai R. Epidemiology and the medical causes of miscarriage. Bailliere's best practice \& research Clinical obstetrics \& gynaecology. 2000 Oct;14(5):839-54.

2. F. Gary Cunningham KJL, Steve L. Bloom, John C. Hanth, Dwight J. Rouse, Catherine Y. Spong, editor. Williams Obstetrics. $23^{\text {rd }}$ ed. United States of America: McGraw Hill Medical; 2010. study done by Sarin et al. showed higher incidence of inflammation in chorionic villous and decidua. ${ }^{16}$

Novak et al. prospective study showed the presence of villous scalloping with trophoblastic invagination was significantly associated with abnormal karyotypes, particularly triploidy, and the demonstration of acute inflammation was seen significantly more often in cases with normal karyotypes. As karyotyping was not done in our study, the association of abnormal karyotype with particular pattern of histopathological changes could not be ascertained. ${ }^{17}$

In the present study, the mean age at the time of abortion was $25.09 \pm 5.58$ years with minimum age was 15 years and maximum age was 45 years. Majority of women belonged to age group $21-30$ years $(62.2 \%)$ while only $2.7 \%$ were above 40 years which shows highly significance. Similar findings were noted in study done by Wang et al. in China in 2003. ${ }^{18}$ However, reports by Nepal Demographic Health survey (NDHS) 2011 has revealed that $7.9 \%$ out of 1245 women were below 20 years, $6.1 \%$ out of 4605 women were between $20-34$ years and $9.9 \%$ out of 505 women were $35-49$ years of age at the time of abortion implying that spontaneous abortion is more common in elderly age group..$^{19}$ This could be attributable to the fact that the NDHS survey was done in different geographical parts of Nepal whereas this study included women with spontaneous abortion around Kavre district only.

Nevertheless, the limited sample size and mono-centered study can effect in the interpretation of the obtained result. Therefore, sample size can be increased to include the range of age groups to incur more concrete result.

\section{CONCLUSION}

Products of conception was the most common finding in spontaneous abortion, while inflammatory infiltrates was the most common changes seen in decidua.

The findings of Hydatidiform mole, choriocarcinoma in cases of incomplete and complete abortions, decidual tissue only without chorionic villi raised suspicion of other pathology requiring further evaluation. The histopathological diagnosis of spontaneous abortion will help in further management of the patient. Further study is required to know the cause of different histopathlogical changes in villi as well as in the decidua.
3. La Rochebrochard E, Thonneau P. Paternal age and maternal age are risk factors for miscarriage; results of a multicentre European study. Human Reproduction. 2002;17(6):1649-56.

4. Osborn JF, Cattaruzza MS, Spinelli A. Risk of spontaneous abortion in Italy, 1978-1995, and the effect of maternal age, gravidity, marital status, and education. American journal of epidemiology. 2000 Jan 1;151(1):98-105. 
5. Regan L, Braude PR, Trembath PL. Influence of past reproductive performance on risk of spontaneous abortion. BMJ (Clinical research ed). 1989 Aug 26;299(6698):541-5.

6. Pasqualotto FF, Sobreiro BP, Hallak J, Pasqualotto EB, Lucon AM. Cigarette smoking is related to a decrease in semen volume in a population of fertile men. BJU Int. 2006;97(2):324-6.

7. Shrestha DR. Reproductive Health: National and International Perspectives. Abortion care. $2^{\text {nd }}$ ed. Sanepa, Lalitpur, Nepal: Sigma General Offset; 2012. p. 253-79.

8. Kesmodel U, Wisborg K, Olsen SF, Henriksen TB, Secher NJ. Moderate alcohol intake in pregnancy and the risk of spontaneous abortion. Alcohol Alcohol. 2002;37(1):87-92.

9. Helgstrand S, Andersen AM. Maternal underweight and the risk of spontaneous abortion. Acta obstetricia et gynecologica Scandinavica. 2005;84(12):1197-201.

10. Alsibiani SA. Value of Histopathologic Examination of Uterine Products after First-Trimester Miscarriage. BioMed Research International. 2014;2014:5

11. Tasci Y, Dilbaz S, Secilmis O, Dilbaz B, Ozfuttu A, Haberal A. Routine histopathologic analysis of product of conception following firsttrimester spontaneous miscarriages. J Obstet Gynaecol Res. 2005;31(6):579-82.

12. Fram KM. Histological analysis of the products of conception following first trimester abortion at Jordan University Hospital. Eur J Obstet Gynecol Reprod Biol. 2002;105(2):147-13.
13. Kohut KG, Anthony MN, Salafia CM. Decidual and placental histologic findings in patients experiencing spontaneous abortions in relation to pregnancy order. Am J Reprod Immunol. 1997 Mar;37(3):257-61.

14. Salmon JE. A non-inflammatory pathway for pregnancy loss: innate immune activation? J Clin Invest. 2004; 114(1):15-7.

15. Haque AU Siddique S, Jafari MM, Hussain I and Siddiqui S. Pathology of Chorionic Villi in Spontaneous Abortions. International Journal of Pathology. 2004;2(1):5-9.

16. Sarin AR, Kaur B, Modi S, Popli R. Histopathological changes in placenta in early pregnancy wastage. Indian J Matern Child Health. 1993;4(3):75-7.

17. Novak R, Agamanolis D, Dasu S, Igel H, Platt M, Robinson $H$, et al. Histologic analysis of placental tissue in first trimester abortions. Pediatr Pathol. 1988;8(5):477-82.

18. Wang X, Chen C, Wang L, Chen D, Guang W, French J. Conception, early pregnancy loss, and time to clinical pregnancy: a populationbased prospective study. Fertility and sterility. 2003Mar;79(3):577-84.

19. Ministry of Health and Population (MOHP) [Nepal] NE, ICF International. Nepal Demographic and Health Survey 2011. Kathmandu, Nepal: Ministry of Health and Population, New ERA, and ICF International, Calverton, Maryland; 2012. 